\title{
O MODELO DE GESTÃO EDUCACIONAL DAS ESCOLAS CIDADÃS INTEGRAIS DA PARAÍBA: ANÁLISE DE UM CADERNO FORMATIVO À LUZ DO ISD
}

\section{THE EDUCATIONAL MANAGEMENT MODEL OF FULL-TIME SCHOOLS IN PARAÍBA: ANALYSIS OF A TEACHER-EDUCATION MANUAL IN THE LIGHT OF SDI}

\author{
Philipe Pereira Borba de Araújo ${ }^{1}$ \\ Filipe Mendes Cavalcanti Leite ${ }^{2}$ \\ Liliane Alves Chagas ${ }^{3}$ \\ Thiago Luís Cavalcanti Calabria ${ }^{4}$
}

\begin{abstract}
RESUMO: Este artigo apresenta uma análise de um dos cadernos de formação desenvolvido pelo Instituto de Corresponsabilidade pela Educação (ICE), intitulado "Modelo de Gestão: Tecnologia de Gestão Educacional", que orienta e, de certa forma, condiciona a gestão das escolas pertencentes ao Programa de Educação Integral na Paraíba. A análise teve por objetivo identificar quais são os princípios, conceitos e fundamentos presentes no documento. Buscou, ainda, desvelar como estão representadas, no documento, as tensões entre as esferas pública e privada, a partir de aspectos enunciativos do texto (vozes e modalizações). Esta pesquisa se insere no campo da Linguística Aplicada (LA) e compartilha da natureza indisciplinar e transgressiva desse campo do saber (MOITA LOPES, 2006; PENNYCOOK, 2006). Desenvolvido à luz do Interacionismo Sociodiscursivo (BRONCKART, 1999, 2006, 2012), este trabalho também se embasa nas contribuições de teóricos da educação, como Ball (2014), Laval (2019) e Libâneo (2016). Na análise, considera-se que o documento ilustra um movimento que busca atuar fortemente na redução da esfera de autonomia das escolas.
\end{abstract}

PALAVRAS-CHAVE: Tecnologia de Gestão Educacional. Gestão escolar. Instituições privadas. Interacionismo Sociodiscursivo.

\begin{abstract}
This article presents an analysis of one of the teacher-education manual developed by the Institute of Co-responsibility for Education (ICE), entitled "Management Model: Educational Management Technology", which guides and, in a way, conditions the management of schools in the Full-Time Education Program in Paraíba. The analysis aimed to identify which are the principles and concepts present in the document. It also sought to reveal how the tensions between the public and private spheres are represented in the document, based on enunciative aspects of the text (voices and modalisations). This research is in the field of Applied Linguistics (LA) and shares the indisciplinary and transgressive nature of this field of knowledge (MOITA LOPES, 2006; PENNYCOOK, 2006). Developed in the light of Sociodiscursive Interactionism (BRONCKART, 1999, 2006, 2012), this work is also based on the contributions of educational theorists, such as Ball (2014), Laval (2019) and Libâneo (2016). The analysis points that the document illustrates a movement that intends to promote a reduction in the sphere of autonomy of schools.
\end{abstract}

KEYWORDS: Educational Management Technology. School management. Private institutions. Sociodiscursive Interactionism.

\footnotetext{
${ }^{1}$ Professor do Centro de Ciências Humanas, Sociais e Aplicadas da Universidade Federal da Paraíba (UFPB). Doutorando em Linguística (UFPB).E-mail: philipe.araujo@academico.ufpb.br. Orcid: https://orcid.org/00000003-3239-8175.

${ }^{2}$ Professor da União de Ensino Superior de Campina Grande. Doutorando em Ciências Jurídicas (UFPB). E-mail: filipimendes@hotmail.com. Orcid: https://orcid.org/0000-0001-9196-7126.

${ }^{3}$ Professora da Secretaria de Estado da Educação e da Ciência e Tecnologia da Paraíba (SEECT/PB). Doutoranda em Educação (UFPB).E-mail: lilianealvesc@gmail.com. Orcid: https://orcid.org/0000-0001-8670-9843.

${ }^{4}$ Professor da SEECT/PB. Mestre em Educação pela Universidade Federal de Pernambuco (UFPE). E-mail: thg.calabria@gmail.com. Orcid: https://orcid.org/0000-0002-0677-6200.
} 
Volume 16 - Número 1 - jan/jul de 2021

\section{Introdução}

As Escolas Cidadãs Integrais $(\mathrm{ECI})^{5}$ apresentam-se como um novo modelo de escola pública no estado da Paraíba, com desenho curricular, estrutura física, modelo de gestão interno e externo, instrumentos de fiscalização e controle, regime de trabalho e objetivos pedagógicos próprios. Por meio de uma parceria público-privada entre a Secretaria de Estado da Educação, Ciência e Tecnologia da Paraíba (SEECT/PB) e o Instituto de Corresponsabilidade pela Educação (ICE), foram implantadas, no ano de 2016, as primeiras ECI no Estado da Paraíba, conforme o Decreto $\mathrm{n}^{\mathrm{o}} 36.408 / 2015$. Inicialmente, foram apenas oito escolas. No ano de 2021, já são mais de 300 escolas implementadas e mais de 74.000 vagas de ensino em tempo integral oferecidas conforme essas diretrizes (JOÃO AZEVEDO..., 2021). Recentemente, viu-se, ainda, a promessa de o modelo das ECI se efetivar como modelo único em todas as escolas estaduais até 2022 (LEITE, 2020).

O ICE é uma organização privada, criada e presidida por Marcos Magalhães (Ex-CEO da Philips). Em seu website, o instituto se diz "uma entidade sem fins econômicos [...] criado em 2003 por um grupo de empresários motivados a conceber um novo modelo de escola e resgatar o padrão de excelência do então decadente e secular Ginásio Pernambucano, localizado em Recife" (ICE, [2015], on-line). Atualmente, o instituto atua em 16 estados e oito municípios brasileiros. O referido instituto oferece apoio técnico para a implementação do modelo, ofertando formação continuada para docentes e gestores escolares, bem como para técnicos da SEECT/PB. Também se responsabiliza pela disponibilização de material teórico para as equipes escolares e pela realização de monitoramentos bimestrais nas unidades escolares, conhecidos como "ciclos de acompanhamento".

Desde a implantação do modelo, são realizados processos de seleção interna de docentes, coordenadores(as) pedagógicos(as), coordenadores(as) administrativos(as) e financeiros(as), bem como de gestores(as) escolares para ocuparem os cargos nas ECI de todo Estado. O material de estudo para a seleção consiste nos cadernos de formação ofertados pelo ICE. Além disso, esses cadernos são consultados para a configuração das diretrizes das Escolas Cidadãs, que são lançadas anualmente desde o ano de 2017 e orientam o fazer pedagógico e a gestão das escolas integrais do estado.

Considerando os impactos da adoção dos livretos do ICE no contexto de trabalho de milhares de docentes do estado da Paraíba, assim como em outros estados, consideramos altamente relevante que se desenvolvam pesquisas para compreender de forma mais aprofundada o que tem sido proposto nesse contexto educativo. Assim, buscando trazer contribuições nesse sentido, nosso artigo apresenta uma análise de um dos livretos do ICE, intitulado "Modelo de Gestão: Tecnologia de Gestão Educacional", com o objetivo de identificar quais são os princípios, fundamentos e rede de influências presentes nesse documento, que orienta e, de certa forma, condiciona a gestão das escolas pertencentes ao Programa de Educação Integral na Paraíba. Buscaremos, ainda, desvelar como estão representadas, no documento, as tensões entre as esferas pública e privada.

\footnotetext{
${ }^{5}$ Existem atualmente três tipos de Escolas Cidadãs na Paraíba: as propedêuticas (ECI), que adotam integralmente o modelo desenvolvido pelo ICE; as técnicas (ECIT), que, além das bases do modelo, também incorporam disciplinas para formação técnica; e as socioeducativas (ECIS), que adaptam o modelo às especificidades do funcionamento dentro de Unidades de Medidas Socioeducativas. Neste texto, usamos o termo ECI para englobar toda a rede de Escolas Cidadãs, e não apenas as escolas propedêuticas.
} 
Volume 16 - Número 1 - jan/jul de 2021

\section{Fundamentação teórica}

Nesta pesquisa, partimos da premissa de que fenômenos sociais, por sua inerente complexidade, requerem uma visão holística a fim de que sejam estudados. Nesse sentido, este artigo se insere no campo da Linguística Aplicada (LA) e compartilha da natureza indisciplinar, mestiça, política, ideológica, e transgressiva desse campo do saber (MOITA LOPES, 2006; PENNYCOOK, 2006). Nessa perspectiva, traremos à baila, neste trabalho, contribuições de teóricos de diversas áreas do conhecimento, partindo de reflexões voltadas ao macrocontexto das reformas no âmbito educacional para as marcas que se fazem presentes nos textos-discursos utilizados nas políticas educacionais no chão da escola.

O modelo das Escolas Cidadãs está inscrito em um contexto amplo de reformas educacionais, ao qual o Brasil tem sido lançado desde a década de 1990. Diversas forças disputam seu lugar na arena de representação e de protagonismo de seus interesses no campo educacional. Das influências, diretas ou sugeridas, de mecanismos multilaterais ao lobby de empresas e institutos privados nacionais dentro de diversas esferas de deliberação administrativas, tanto no Ministério da Educação quanto nas Secretarias estaduais, a batalha por um lugar de destaque nas finanças e nos discursos educacionais tem se revelado um jogo de forças complexo e multifacetado, em que a iniciativa privada tem ganhado a dianteira.

Nesse processo de inserção dos setores empresariais na educação, por meio de institutos/fundações/organizações sociais de interesse público, apresentam-se soluções com matriz ideológica própria e que muitas vezes se traduzem em políticas públicas voltadas a setores específicos da sociedade. Libâneo (2016) sugere que as políticas educacionais aplicadas às escolas, nas últimas décadas, têm sofrido influência direta de organismos multilaterais como Organização das Nações Unidas para a Educação, Ciência e a Cultura (UNESCO), Banco Mundial (BM), Fundo Monetário Internacional (FMI), Banco Interamericano de Desenvolvimento (BID) e Organização para a Cooperação e Desenvolvimento Econômico (OCDE). Essa arquitetura global de relações políticas apresenta indícios de uma nova forma de relação entre o Estado, o mercado e a sociedade civil (BALL, 2014).

Compreendemos que esse processo de internacionalização de políticas públicas e do seu fluxo em direção à periferia do capitalismo, protagonizado por agências nacionais e internacionais, se traduz em novos formatos de sistemas e instituições de ensino, em novos currículos, em novas formas de gestão pedagógica, em novas formas de governança e no estabelecimento de objetivos/metas para fins de cobrança e padronização. O fio condutor dessas políticas é a "modernização do Estado", algo que se justifica, supostamente, pelo baixo desempenho apresentado nas avaliações externas. É por meio desse diagnóstico, elaborado pelo mercado, que se apresentam soluções privadas para questões públicas.

Nesse sentido, compreendemos que o grau de inserção das fundações filantrópicas no processo de desenvolvimento das políticas públicas educacionais se mostra como algo relevante, não só no âmbito estadual, mas também internacional, pois dá indícios de disseminação de ideais conservadores, de uma agenda política neoliberal e de mais uma oportunidade de negócios para empresas (LAVAL, 2019). Esse fenômeno fomenta um novo modelo de governança e de novas formas de organização do trabalho pedagógico e de gestão escolar, trazendo consequências diretas para a educação pública no Brasil e, particularmente, na Paraíba.

Grande parcela desses processos graduais de indefinição de contornos que distinguem o público do privado se manifestam por meio de ações de linguagem. Rodrigues (2019) vai ao cerne dessa questão, ajudando-nos a perceber como os livretos da Escola da Escolha, produzidos pelo ICE, trazem, em seus pressupostos, léxico, gramática, valores e intenções, elementos da gestão da iniciativa privada, das grandes empresas e corporações mundiais. 
Assim, evidencia-se que um olhar mais apurado para os usos da linguagem pode trazer contribuições ímpares para que se evidenciem essas marcas com mais clareza.

É nessa direção que, dentro do campo da LA, nos apoiamos nos pressupostos e nas discussões do Interacionismo Sociodiscursivo (ISD) (BRONCKART, 1999, 2006, 2012). Para este artigo, serão fundamentais os conceitos de mecanismos enunciativos, mais especificamente, as vozes e modalizações, que explicaremos nos parágrafos a seguir.

Para Bronckart (1999), a linguagem se materializa em textos em três níveis, compondo o que o autor denomina arquitetura interna dos textos. No nível mais profundo, a infraestrutura geral do texto coloca em funcionamento a representação dos mundos discursivos; no nível intermediário, os mecanismos de textualização articulam as partes que compõem o texto; e no nível mais superficial, os mecanismos enunciativos contribuem para garantir-lhe coerência pragmática. Essa visão global sobre o texto, que busca compreender o agir linguageiro sempre em relação com o contexto sócio-histórico, oferece subsídios para a análise do agir humano mediado pela linguagem.

Conforme o autor, os mecanismos enunciativos (vozes e modalizações) contribuem para o esclarecimento dos posicionamentos enunciativos (isto é, quais são as instâncias que assumem o que é enunciado no texto? Quais são as vozes que aí se expressam?) e traduzem as diversas avaliações (julgamentos, opiniões, sentimentos) sobre alguns aspectos do conteúdo temático. Nesse sentido, esses mecanismos visam a orientar a interpretação do texto por seus destinatários.

Como explica Bronckart (1999, p. 326), vozes são "entidades que assumem (ou às quais são atribuídas) a responsabilidade do que é enunciado". Reichmann $(2014$, p. 36) ressalta que as vozes "inscrevem as instâncias enunciativas, assumindo a responsabilidade pelo que é dito (ou pensado), como também a responsabilidade pela interação entre o produtor do texto e destinatários", podendo ser categorizadas como: vozes sociais (que não intervêm como agentes no percurso temático; instâncias externas de avaliação), vozes de personagem (implicadas nos acontecimentos do conteúdo temático) ou vozes do autor empírico (da pessoa que cria o texto, que comenta ou avalia o que é dito).

Dentre os mecanismos enunciativos, existem também as modalizações, que podem ser agrupadas em quatro subconjuntos: (1) modalizações lógicas (que apresentam valor de verdade - certo, possível, provável, improvável); (2) modalizações deônticas (que apresentam valores sociais - permitido, proibido, necessário, desejável); (3) modalizações apreciativas (que apresentam valores subjetivos - bons, maus, estranhos); e (4) modalizações pragmáticas (que apresentam responsabilidade de um personagem em relação ao processo de que é agente capacidade de ação / poder fazer, intenção / querer fazer, e as razões / dever fazer). Neste artigo, veremos como as vozes e modalizações são mobilizadas no objeto analisado e como contribuem na construção de sentidos.

\section{Procedimentos metodológicos}

Tendo em vista o fato de que a atuação do ICE e de outros institutos do terceiro setor na formulação de políticas para o ensino médio é um fenômeno bastante recente, esse tema ainda é pouco explorado em pesquisas acadêmicas. Por esse motivo, escolhemos realizar um estudo que pode ser descrito, em termos metodológicos, como uma pesquisa exploratória. Esse tipo de investigação se caracteriza por "desenvolver, esclarecer e modificar conceitos e ideias, tendo em vista a formulação de problemas mais precisos ou hipóteses pesquisáveis para estudos posteriores" (GIL, 2008, p. 46). Esta pesquisa pode ser caracterizada, ainda, como uma pesquisa documental. Como explicam Silva e colaboradores (2009, p. 4557), esse tipo de pesquisa "permite a investigação de determinada problemática não em sua interação imediata, mas de 
Volume 16 - Número 1 - jan/jul de 2021

forma indireta, por meio do estudo dos documentos que são produzidos pelo homem e por isso revelam o seu modo de ser, viver e compreender um fato social".

Embora o modelo da Escola da Escolha, desenvolvido pelo ICE, conte com dezenas de cadernos de formação, escolhemos aquele que trata da gestão escolar, vez que é o responsável por estruturar a configuração hierárquica e os papéis de cada ator dentro e fora da escola. É ele, também, que esquematiza os principais instrumentos administrativos e pedagógicos a serem utilizados para o acompanhamento das metas e resultados pactuados (Plano de Ação da escola, Programas de Ação dos/as docentes; guias de aprendizagem, dentre outros). Nos termos do próprio caderno,

o Modelo de Gestão da Escola da Escolha, intitulado Tecnologia de Gestão Educacional - TGE, se apresenta como sendo a base na qual o Modelo Pedagógico se alicerça para gerar o trabalho que transformará toda a "intenção educativa" em "efetiva ação" traduzida em resultados tangíveis e mensuráveis. (ICE, 2019, p. 13)

O caderno de formação "Modelo de Gestão: Tecnologia de Gestão Educacional”, de autoria de Alberto Chinen, João Freitas, Renata Campos, Tadeu Veiga e Thereza Barreto, é composto de três partes e cerca de 70 páginas. A primeira parte, intitulada "A Gestão na Escola da Escolha", apresenta brevemente o contexto de surgimento do Modelo de Gestão em 2003, em Pernambuco, e lista os princípios e conceitos da TGE. Na segunda parte, "Liderança Servidora e Motivação", discutem-se a concepção de "liderança servidora", subjacente ao modelo, e a noção de motivação à luz das perspectivas de Maslow e de Vroom. Na terceira e última parte, "Planejamento e Operacionalização", apresenta os instrumentos da TGE (Programa de Ação, Agenda, PDCA e Guia de Ensino e de Aprendizagem).

Para o desenvolvimento deste artigo, foi feita, inicialmente, uma leitura atenta de todo o documento, dando-se destaque a trechos que chamaram a nossa atenção, seja pela configuração textual (léxico utilizado e recursos linguístico-discursivos), seja pelo conteúdo temático (agentes, personagens, vozes sociais e pressupostos teóricos). Posteriormente, procedemos a um agrupamento dos destaques, reunindo-os em categorias por critérios de proximidade.

Nosso olhar para o objeto empírico foi guiado pela premissa teórico-metodológica do ISD, segundo a qual a análise de textos segue uma abordagem descendente, isto é, a análise vai das condições de produção do texto (parâmetros do mundo físico e sociossubjetivo) para a infraestrutura textual. Em outras palavras, parte-se das atividades sociais para as atividades de linguagem (BRONCKART, 2006, 2012).

Nesse sentido, nossa análise se volta, num primeiro momento, para os pressupostos do modelo da Escola da Escolha, compreendendo suas conexões com a sociedade, a partir das vozes sociais que são mobilizadas no texto. Em seguida, buscamos descrever como são apresentadas as finalidades da escola e as vozes sociais e de personagem que permeiam o texto. Por fim, buscamos pistas sobre a figura dos "investidores sociais" ou "parceiros", que aparecem recorrentemente no texto e analisamos os contextos de uso das modalizações mais utilizadas.

\section{Análise}

\subsection{Onde estamos? Representações de sociedade como justificativa e ponto de partida.}

Interessa-nos neste ponto compreender como a realidade social é representada no documento e como as questões sociais são mobilizadas no texto para justificar a adoção do 
Volume 16 - Número 1 - jan/jul de 2021

modelo proposto. Já em seus parágrafos iniciais, o documento justifica as necessidades de formação integral a partir das necessidades da sociedade do século XXI, como se vê no excerto a seguir:

Excerto 1: A sociedade do século XXI, fundamentada no conhecimento, na fluidez de relacionamentos e na adaptabilidade às mudanças, demanda cada vez mais de seus partícipes uma formação integral. (ICE, 2019, p. 19)

Muitos teóricos da modernidade, dentre eles Zygmunt Bauman (2001, 2004), criticam a fragilidade dos laços e das relações na sociedade contemporânea. $\mathrm{O}$ teor dessas críticas se assenta na denúncia das inseguranças em que são lançados os indivíduos, em virtude do avanço das políticas neoliberais por sobre diversos campos, seja dos direitos até a construção das subjetividades. O trecho apresentado, longe de se alinhar a essas críticas, parece enfatizar a necessidade de os sujeitos se adaptarem às mudanças, tomando-as como inexoráveis. Nos termos de Laval (2019, p. 41), "[a] principal competência, a metacompetência, consistiria em 'aprender a aprender' para enfrentar a incerteza alçada à exigência permanente da existência humana e da vida profissional. A grande diretriz da escola é a empregabilidade individual".

Em diversos momentos, o livreto menciona o termo "educação de qualidade", como vemos nos excertos a seguir. Entretanto, em nenhuma ocasião explica o que essa expressão significa. Essa ausência de definição sobre o que viria a ser uma "educação de qualidade" parece ressoar no texto como uma marca de diferenciação entre aquilo que o ICE propõe e o que é vivido na realidade atual das escolas que não adotam o modelo.

Excerto 2: Reunir as condições para atuar nesse cenário, exige a oferta de uma escola totalmente comprometida com sua atividade-fim, isto é, trabalhar incansavelmente pela busca e manutenção de uma educação de qualidade. (ICE, 2019, p. 19)

Excerto 3: A Escola da Escolha nasceu motivada pela criação de uma causa em torno da oferta de uma educação de qualidade para todos. (ICE, 2019, p. 46)

Além disso, é interessante a inserção dos advérbios "totalmente" e "incansavelmente", no excerto 2, para configurar o modo como o trabalho docente deve ser realizado. Ao lembrarmos a forma como a dinâmica pedagógica se concretiza nas escolas integrais que adotam as diretrizes do Instituto, poder-se-ia imaginar que o "incansavelmente" não surge em vão. Conforme a Lei 11.100/18, do estado da Paraíba, a jornada de trabalho dos professores das ECI conta com 45 horas-aula obrigatoriamente cumpridas na escola.

\subsection{Onde queremos chegar? Dos sonhos da comunidade escolar e à visão da Secretaria de Educação.}

Até este ponto da análise, vimos como alguns elementos da realidade social são invocados no texto para justificar a implementação do modelo proposto pelo ICE. Saindo desse ponto de partida, buscamos, agora, compreender onde essa proposta educativa pretende chegar, ou seja, quais finalidades, para as escolas públicas, são vislumbradas a partir do texto.

Ao longo de todo o material, a finalidade última da escola parece se alternar entre dois polos. Se, nas páginas iniciais, a TGE e seus instrumentos são apresentados como recursos para "materialização do projeto de vida de uma comunidade" (excerto 4) ou trazer resultados "comprometidos com sua visão" (excerto 5), mais adiante, fica evidente que não é a visão de 
Volume 16 - Número 1 - jan/jul de 2021

futuro da comunidade escolar que se almeja alcançar, mas aquela pré-estabelecida pela Secretaria de Educação (excertos 6 a 8).

Excerto 4: O Plano de Ação da Escola é a materialização de um sonho coletivo, do Projeto de Vida de uma comunidade. (ICE, 2019, p. 21)

Excerto 5: [A] Tecnologia de Gestão Educacional é movida pela determinação em construir um novo paradigma para a gestão escolar, criando a condição para que o Modelo de Gestão "sirva" ao Modelo Pedagógico, implicando em processos que levarão a escola a gerar os resultados comprometidos com a sua visão. (ICE, 2019, p. 20, grifo nosso)

Excerto 6: Planejar é o momento de refletir, de discutir com a equipe a visão de futuro estabelecida pela Secretaria de Educação para a Escola da Escolha e de decidir como desdobrá-la em estratégias e ações a serem operacionalizadas no cotidiano escolar. (ICE, 2019, p. 53, grifo nosso)

Excerto 7: É importante ressaltar que a visão de futuro e as premissas no Plano de Ação da Secretaria de Educação não devem ser alteradas, pois se trata de uma expressão da Secretaria. (ICE, 2019, p. 54, grifo nosso)

Excerto 8: É necessário por a disposição [sic] do gestor e de sua equipe um conjunto de ferramentas gerenciais que permitam dirigir a escola de forma estruturada para atingir a visão estabelecida pelo município e/ou estado. (ICE, 2019, p. 16, grifo nosso)

Ressaltamos que fixar os objetivos da gestão escolar na concretização dos planos da Secretaria de Educação implica redução da esfera de autonomia da escola, mitigando aquilo que a Constituição Federal de 1988 assegura, em seu art. 206, e que a Lei de Diretrizes e Bases da Educação (Lei 9.394/96) preceitua nos seus artigos $3^{\circ}$ e 15 , garantindo pluralismo de ideias e de visões pedagógicas e autonomia da gestão escolar.

Outras passagens do texto permitem entrever o sentido que o ICE atribui a uma escola exitosa. Por exemplo, no excerto 9, vemos que "a expressão máxima" do sucesso da replicação do modelo se realiza na elaboração do Projeto de Vida dos alunos, conforme as regras, parâmetros e valores preconizados pelo Plano de Ação da própria escola, que, por sua vez, espelha o próprio modelo.

Excerto 9: A expressão máxima dessa abordagem metodológica configura-se no Projeto de Vida dos estudantes, pois este se assemelha à elaboração do Plano de Ação da própria escola, no qual estudantes, educadores e gestores se utilizam da mesma linguagem e dos mesmos instrumentos para planejar, definir metas, gerenciar suas atividades e avaliar seus resultados." (ICE, 2019, p. 21)

Em outros termos, o que se espera é que o aluno internalize, cada vez mais, a forma de pensar e de gerir a própria vida pessoal, valendo-se "da mesma linguagem e dos mesmos instrumentos" utilizados pelos professores e gestores escolares no contexto de trabalho. Assim sendo, como numa cascata, o ICE busca imprimir nos espíritos a marca do seu projeto. Como explicado por Araújo e Leite (2020, p. 295), a ideologia neoliberal,

[...] mais que uma doutrina econômica, caracteriza-se, em última instância, como um projeto de fabricação de um novo indivíduo, como tão claramente resumiu Margaret Thatcher em sua célebre frase: "Economics are the method: 
Volume 16 - Número 1 - jan/jul de 2021

the object is to change the soul". O projeto neoliberal almeja produzir, portanto, não somente uma determinada maneira de representar o mundo e de agir, mas, em um nível ainda mais profundo, uma representação de si e uma autogestão comportamental e emocional que simultaneamente produz e é produzida por esse modelo social [...].

Mais adiante, o livreto apresenta os três níveis do ciclo de vida de uma escola que está se adaptando ao modelo: sobrevivência $\left(1^{\circ}\right.$ ano), crescimento $\left(2^{\circ}\right.$ ano) e sustentabilidade $\left(3^{\circ}\right.$ ano). Vejamos como esse terceiro nível é descrito.

Excerto 10: A escola se torna sustentável porque criou as condições, pelos resultados alcançados e que ela passou a exibir, de se manter operando no sistema. Isso demonstra para a sociedade, para o gestor público e investidores sociais a quem ela responde, o que se espera dela enquanto instituição pública de educação. Ou seja, ela gera valor ao sistema e prova que não é apenas alimentada/mantida pelo sistema público que a financia, mas também alimenta esse mesmo sistema público porque oferece à sociedade que a financia (pelo pagamento dos seus tributos) os resultados que lhes são devidos. A escola é sustentável porque retribui sob a forma de resultados àquele que a mantém por meio de recursos advindos dos tributos. (ICE, 2019, p. 32-33)

Ao descrever as escolas no $3^{\circ}$ ano de implementação como sustentáveis, esse trecho acaba por sugerir uma categorização das escolas, de modo que haveria, portanto, escolas sustentáveis e escolas não sustentáveis. Assim, algumas escolas "retribuem" os investimentos, enquanto as demais não teriam "condições [...] de se manter operando no sistema". Nesse sentido, caberia dizer que apenas escolas que "geram valor ao sistema" seriam dignas de permanecer funcionando. Chama a atenção a forma como as vozes sociais (BRONCKART, 1999) são utilizadas no texto: "sociedade", "gestor público" e "investidores sociais" são elencados como atores aos quais a escola deve "responder". Nessa altura do texto, os "investidores sociais" ainda não estão postos de maneira clara, mas vão gradativamente ganhando espaço nas páginas seguintes. Ainda, a ideia de que a escola deve retribuir "àquele que a mantém por meio de recursos advindos dos tributos" reproduz uma lógica do investimento privado para a escola pública. A escola aqui, deixa de ser encarada como um direito público e universal, e passa a ter sua existência ameaçada ou questionada, caso os resultados apresentados não apeteçam aos "investidores".

4.3 Que vozes estão em cena? Dos investidores sociais às redes de influência corporativas nas reformas educacionais.

Os "investidores sociais" são mencionados no texto em diversas passagens e em infográficos. A Fig. 1, a seguir, apresenta o "ciclo virtuoso", que, conforme o manual, "[...] é um importante princípio da TGE, [pois] evidencia as relações existentes entre gestão pública, escola/estudante, investidores sociais e comunidade, e como estas se retroalimentam [...]" (ICE, 2019, p. 23). 
Volume 16 - Número 1 - jan/jul de 2021

Figura 1 - O ciclo virtuoso

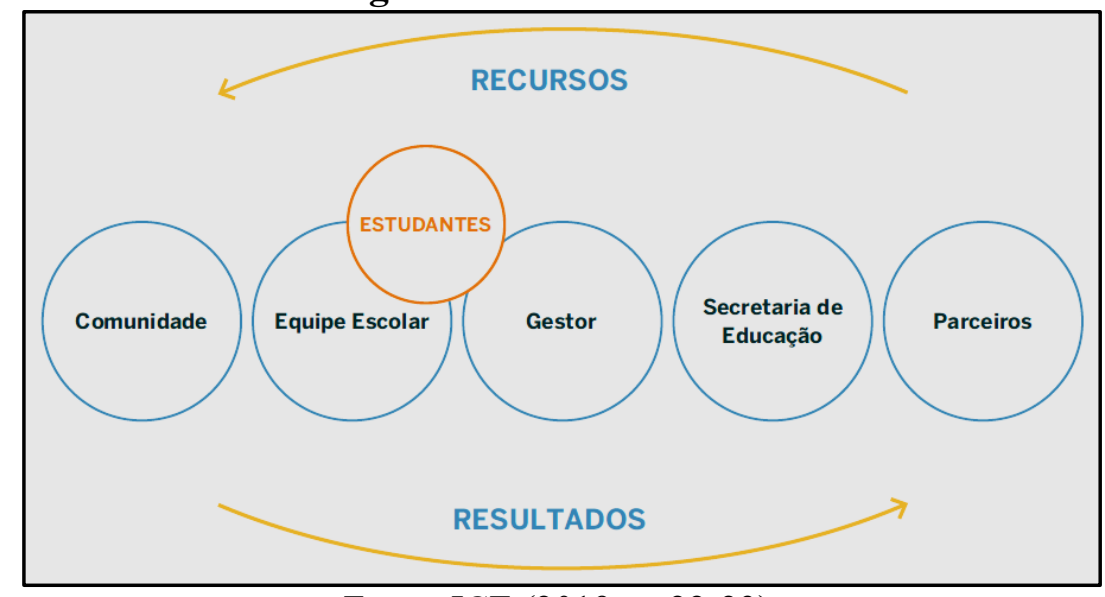

Fonte: ICE (2019, p. 22-23).

De acordo com o infográfico, os recursos que financiam as escolas seguem dos parceiros para a equipe escolar e a comunidade, enquanto os resultados seguem na direção oposta, da escola para a secretaria de educação e os parceiros. O excerto 11 explica os resultados esperados nessa relação:

\section{Excerto 11:}

Em vista disso, cria-se um Ciclo Virtuoso, produtor de riqueza material e moral:

- Os estudantes bem formados impactam positivamente a comunidade em que vivem nas dimensões política, econômica, social e cultural;

- Os investidores sociais (parceiros) interagem e percebem claramente, ao longo do tempo, os benefícios socioeducacionais originados pela replicabilidade do Modelo nas demais escolas de uma rede pública de ensino; - A escola e a comunidade estabelecem um processo progressivo de aproximação tendo no exercício de uma educação de qualidade o elo entre pais e responsáveis e educandos;

- A gestão pública maximiza seus investimentos sociais, empregando de maneira eficaz, eficiente e efetiva os tributos recolhidos da sociedade. (ICE, 2019 , p. 23, grifos nossos)

Excerto 12: O Relatório Parcial e Anual de Resultados deve ser sucinto, objetivo e oferecer subsídios para o ajuste do Plano de Ação do ano seguinte, além de possibilitar à Secretaria de Educação e aos investidores sociais o acompanhamento dos resultados pactuados. (ICE, 2019, p. 67)

É importante notar que, na estruturação desse excerto, os investidores são mencionados antes da relação escola-comunidade e antes da gestão pública. Ainda, o trecho "percebem claramente" evidencia que o modelo está em busca de resultados mensuráveis especificamente para os "investidores sociais", como já se poderia inferir a partir do infográfico que apresentamos mais acima. Conforme os excertos 11 e 12 e a Fig. 1, os investidores são o fim a que deve responder a escola pública: deles partiriam os recursos e para eles retornariam os resultados por eles esperados. Essa relação se evidencia ainda mais na Fig. 2, a seguir: 
Volume 16 - Número 1 - jan/jul de 2021

Figura 2 - Parceria e corresponsabilidade

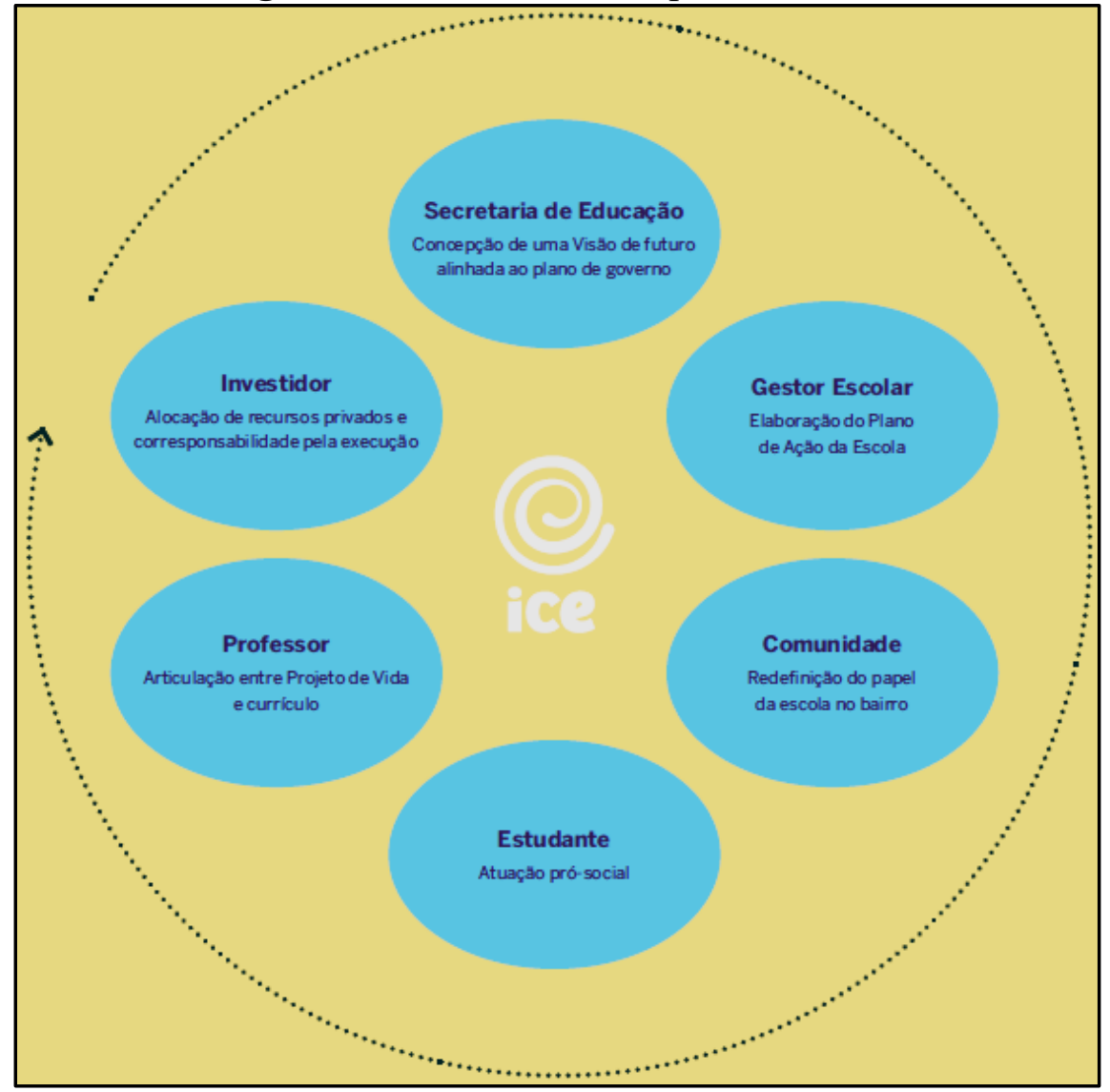

Fonte: ICE (2019, p. 35).

O infográfico mostra que o investidor é o ator responsável pela "alocação de recursos privados e corresponsabilidade pela educação". Note-se ainda que uma seta circular remete à ideia de um ciclo que se inicia e termina nos investidores. É a partir desse ponto que se pode inferir que o uso do termo "investidor" ou "parceiro" ao longo de todo o manual se refere às empresas que financiam institutos como o ICE.

Além desses investidores, é importante perceber que outros atores aparecem no texto. A figura dos investidores é abstrata e nunca pormenorizada; isto é, não é possível compreender a partir da leitura do texto quem esses investidores são. No entanto, por meio da mobilização que o texto faz de alguns autores como vozes de personagem (BRONCKART, 1999), a rede de conexões entre o ICE e esses investidores começa a se delinear. No caderno de formação, apenas oito autores são citados. Elencamo-los a seguir (Quadro 1).

Quadro 1 - Autores citados no caderno de formação "Modelo de Gestão: Tecnologia de Gestão Educacional"

\begin{tabular}{|l|l|l|}
\hline AUTOR & ÁREA DE CONCENTRAÇÃO & OBRA / CONCEITO CITADO \\
\hline $\begin{array}{l}\text { Antonio Carlos } \\
\text { Gomes da Costa }\end{array}$ & $\begin{array}{l}\text { Educador e ativista social. Um dos redatores do } \\
\text { Estatuto da Criança e do Adolescente. }\end{array}$ & Pedagogia da presença (2001). \\
\hline Bruno Silveira & $\begin{array}{l}\text { Advogado e ex-vice-presidente da Fundação } \\
\text { Emílio Odebrecht. Colaborou com a fundação do } \\
\text { Instituto Ayrton Senna. }\end{array}$ & $\begin{array}{l}\text { Responsabilidade social no } 3^{\circ} \\
\text { setor. }\end{array}$ \\
\hline Otto Scharmer & $\begin{array}{l}\text { Economista e professor do MIT. Convidado pela } \\
\text { Natura para desenvolvimento de projetos no }\end{array}$ & Teoria U (2010). \\
\hline
\end{tabular}


Volume 16 - Número 1 - jan/jul de 2021

\begin{tabular}{|l|l|l|}
\hline & Brasil. & \\
\hline Abraham Maslow & Psicólogo. & Hierarquia das necessidades. \\
\hline Victor Vroom & Professor da área da administração. & $\begin{array}{l}\text { Teoria da expectativa e processos } \\
\text { motivacionais. }\end{array}$ \\
\hline Robert K. Greenleaf & Pesquisador da área da administração. & The servant as leader (1970). \\
\hline James C. Hunter & Palestrante da área da administração. & O monge e o executivo (1998). \\
\hline Peter Drucker & Professor e consultor da área da administração. & Noções de gestão. \\
\hline
\end{tabular}

Fonte: elaborado pelos autores.

Em relação aos autores citados, desponta o fato de a vasta maioria ser da área da administração de empresas e apenas um deles ser um pensador da educação (Antonio Carlos Gomes da Costa). Cabe ressaltar que, nas instâncias do texto em que Gomes da Costa é citado, ele aparece mais recorrentemente como sujeito de agradecimentos a quem se credita a paternidade do modelo pedagógico, e não como teórico cujas formulações são debatidas. Por outro lado, há, em relação aos demais autores, uma evidente transposição direta de ideias e conceitos advindos do âmbito gerencial empresarial. Por meio desse tipo de recurso, os autores do texto pretendem uma equivalência entre a gestão escolar e a administração de uma instituição privada.

Ressalte-se também as redes que interconectam alguns desses atores. Em sua página na $w e b$, o ICE cita, entre seus parceiros estratégicos o Instituto Natura e o Instituto Sonho Grande. O Instituto Natura aparece também na lista de "investidores", juntamente a outras instituições, tais como o Itaú BBA, a Fiat e a EMS. Não por acaso, a teoria de Otto Scharmer, que tem contribuído como consultor da Natura nos últimos anos, surge com tanta ênfase no texto.

O relatório "Educação: um tesouro a descobrir", realizado pela UNESCO e coordenado por Jacques Delors, também é mencionado no caderno. Como mencionamos mais acima, a participação de organismos internacionais, tais como UNESCO, BM, FMI e BID já foi apontada por Libâneo (2016) e por outros autores como um fator relevante para a promoção de reformas educacionais nas últimas décadas.

Algumas ausências também chamam a atenção no caderno analisado. A TGE deve sua origem à Tecnologia Empresarial Odebrecht, desenvolvida pela empresa homônima, como afirma o próprio ICE, em um de seus manuais mais antigos: "Com base na Tecnologia Empresarial Odebrecht (TEO) foi sistematizada uma variante a ser utilizada no ambiente escolar" (ICE, [2008], p. 4). Nesse mesmo documento, o Instituto agradece ao "Dr. Norberto Odebrecht, por permitir que utilizássemos a TEO como matriz para a sistematização do presente modelo" (ICE, [2008], p. 4). No caderno que analisamos, não há quaisquer referências à Odebrecht ou à sua centralidade na criação da TGE. O único link remanescente é o agradecimento a Bruno Silveira, ex-vice-presidente da Fundação Odebrecht e coautor de obras publicadas em parceria com Gomes da Costa, que publicou também sob o selo da fundação.

\subsection{Indicadores, metas e estratégias para quem? A léxico-gramática empresarial.}

Seria de se esperar que um documento construído a partir de teorias advindas da área negocial e da administração, criado com a íntima participação de "investidores" nos moldes de uma matriz desenvolvida por uma das maiores corporações nacionais, apresentasse, invariavelmente, em seu vocabulário, fortes indícios de transposição de uma gramática 
Volume 16 - Número 1 - jan/jul de 2021

privatista para algo que é eminentemente público. De fato, esse léxico permeia todo o texto, como se pode observar nos excertos a seguir.

Excerto 13: Essa estrutura deverá garantir que missão, objetivos, metas, indicadores, estratégias e ações estejam alinhados e claramente definidos em todas as instâncias da escola, de modo que todos possam, com clareza, compreender o seu papel e contribuir objetivamente para a consecução dos resultados esperados para que sejam medidos, avaliados e reconhecidos. (ICE, 2019, p. 16, grifos nossos)

Excerto 14: Todo o esforço da Escola gera um resultado, mensurado por intermédio de um ou mais indicadores e acompanhado por meio das metas planejadas. (ICE, 2019, p. 74, grifos nossos)

Excerto 15: De posse dos dados, analisados e transformados em informações subsidiárias da tomada de decisão, gestores podem pilotar/administrar com mais clareza e segurança as organizações. Conforme a frase proferida pelo autor e professor americano Peter Drucker: 'se você não pode medir, você não pode gerenciar'. (ICE, 2019, p. 78, grifo no original)

\section{Excerto 16:}

A seguir conheceremos alguns reflexos concretos de um processo de delegação exitoso:

- Aprofundamento do senso de eficácia;

- Intensificação dos sentimentos de pertencimento e lealdade

à escola;

- Construção conjunta dos indicadores de desempenho;

- Geração de sentimentos de autoestima e orgulho coletivos;

- Entendimento das expectativas referentes ao desempenho;

- Surgimento do espírito de equipe [...].

(ICE, 2019, p. 27, grifos nossos)

Um artigo de Santos (2003) endossa a caracterização dos termos acima negritados como oriundos tipicamente da área da administração empresarial. Dentre os substantivos mais comuns no corpus analisado pela autora, estão termos como: gestão, desempenho, líder, visão, decisões, recursos, resultados e planejamento. Um artigo que analisa os termos mais comuns na Tecnologia Empresarial Odebrecht (LAMB et al., 2018) encontrou dentre os termos mais utilizados no corpus as seguintes palavras: líder, resultado, organização, equipe, programa de ação, espírito de servir, delegação.

Nota-se também, a partir da leitura dos excertos acima apresentados, uma dinâmica inversa de responsividade imposta aos agentes públicos por meio do modelo do ICE. Deseja-se que os gestores cumpram sua "missão", de maneira eficaz, em atenção aos "objetivos", "metas", "indicadores" e "estratégias" traçadas à luz do modelo, indicando, assim, que a atuação das escolas públicas estaria, patentemente, a serviço da iniciativa privada. Isso contraria o que a própria LDB preceitua no seu art. $7^{\circ}$, III, ao garantir à iniciativa privada a possibilidade de oferta da educação, mas garantindo ao Poder Público a prerrogativa de fiscalização de seu funcionamento e avaliação da qualidade. Insinua-se, por meio dessa estratégia, uma inversão da ordem das coisas legalmente estabelecida.

Sendo assim, também vale a pena analisar, a partir das modalizações presentes no texto, como os autores situam os polos que obrigam e são obrigados a prestar contas de suas atuações. Predominam, ao longo do texto, modalizações deônticas (BRONCKART, 1999) em diversas passagens, que sugerem, ora aos gestores, ora ao corpo docente, ora a toda a comunidade escolar, as ações que devem ser realizadas. 
Volume 16 - Número 1 - jan/jul de 2021

Excerto 17: O estudante e o provimento de uma educação de qualidade devem ser a centralidade da organização escolar - o que ocupa o tempo, a mente e os corações de cada um dos membros da Equipe Escolar, de acordo com suas áreas específicas. A organização escolar deve gerar resultados, satisfação da comunidade (entenda-se sociedade) pelo desempenho dos estudantes, educadores e gestores. Todos devem estar a serviço da comunidade e se sentir realizados pelo que fazem e pelos resultados que obtêm. (ICE, 2019, p. 22 , grifos nossos)

Excerto 18: [N]a transição para o segundo nível (Crescimento), espera-se que a escola tenha entendido plenamente os Princípios Educativos do Modelo, adquirido domínio das Metodologias de Êxito, consolidado suas rotinas, sua forma de se organizar, de se comunicar, etc. É também no segundo nível que a Equipe Escolar deve estar cada vez mais em busca do autodesenvolvimento e do aperfeiçoamento pessoal e profissional. (ICE, 2019 , p. 32, grifos nossos)

Excerto 19: Tanto na escolha em ingressar como por permanecer na equipe, o bom profissional deve refletir o quanto essa causa faz sentido para sua realização pessoal, pois essa deve ser sua principal fonte de motivação para a dedicação integral requerida pela escola. (ICE, 2019, p. 46, grifos nossos)

Excerto 20: A adoção de atitudes condizentes com os princípios do Modelo da Escola da Escolha é imprescindível para o sucesso da implantação. (ICE, 2019, p. 71, grifo nosso)

Nos excertos 17 a 20, vemos que diversos recursos linguísticos são utilizados nas modalizações deônticas, sendo a construção "deve $(\mathrm{m})$ + infinitivo" a mais comumente utilizada. Outras formas, como "espera-se que" (excerto 18) e "é imprescindível” (excerto 20) também são recorrentes. Ressaltamos, que, nos excertos acima, muitos sintagmas verbais (entender os princípios, consolidar as rotinas, gerar resultados) e nominais (atitudes condizentes, o bom profissional) utilizados nessas construções raramente remetem a um processo reflexivo ou crítico; pelo contrário, quase sempre sugerem uma mera aceitação do modelo.

Observamos também que a escola e seus profissionais ocupam o polo sobre o qual são lançadas as expectativas e as cobranças de alinhamento e adequação ao modelo. Não encontramos nenhum enunciado indicando responsabilidades ou atribuições do próprio ICE ou dos "investidores sociais". Contraditoriamente, na Fig. 2, o ICE aponta os "investidores" como corresponsáveis, no entanto, nenhuma atribuição concreta lhes é atribuída. Infere-se, assim, que aos investidores são creditados os eventuais bônus pelos resultados alcançados, restando à comunidade escolar as cobranças.

\section{Considerações Finais}

Neste artigo, analisamos o caderno de formação "Modelo de Gestão: Tecnologia de Gestão Educacional", desenvolvido pelo Instituto de Corresponsabilidade pela Educação e utilizado como guia para a elaboração das ferramentas da gestão escolar em centenas de escolas estaduais da Paraíba. Nossa pesquisa teve por objetivo identificar premissas, atores e fundamentos presentes nesse documento. 
Volume 16 - Número 1 - jan/jul de 2021

Em nossa análise, diversas ausências saltam aos olhos. Não há qualquer menção à noção de gestão democrática; não há uma definição sobre o que significa "educação de qualidade", expressão recorrente no texto (o termo "qualidade" aparece 15 vezes); não se evidencia com clareza quem seriam os "parceiros" ou "investidores sociais"; e as origens da TGE nos moldes da tecnologia de gestão desenvolvida pela Odebrecht são deliberadamente ocultadas.

Se algumas palavras são postas à margem, outras se destacam pela abundância. A palavra "resultado(s)", por exemplo, é repetida à exaustão, mais de uma centena de vezes. Esse foco em resultados mensuráveis ("se você não pode medir, você não pode gerenciar") parte da ideia de que a escola deve devolver aos "parceiros" os investimentos nela efetuados. Aplica-se, assim, a lógica do investimento privado à educação pública, a ponto de se questionar a "sustentabilidade" de escolas que não apresentem os resultados esperados por esses atores. A escola se transforma, desse modo, em uma fábrica de índices, resultados numéricos, metas e indicadores para investidores.

Sublinhamos que o que não está dito, mas se pode inferir, é que os problemas ou as dificuldades que as escolas públicas enfrentam seriam uma questão que pode ser resolvida por meio de um novo formato de gestão, mais alinhada à configuração de uma gestão privada. Está implícito que a solução para os problemas da educação é a troca do modelo de gestão, visto que não há menções a investimento público em profissionais, na infraestrutura ou nas outras instâncias da vida.

Enquanto a visão de futuro da Secretaria de Educação "não pode ser alterada" e os "parceiros corresponsáveis" não têm atribuições claras, à equipe escolar, não faltam obrigações: "otimizar processos", "consolidar rotinas", "entender os princípios do modelo" e, último mas não menos importante, "gerar resultados". Consideramos, assim, que o documento ilustra um movimento que busca atuar fortemente na redução da esfera de autonomia das escolas.

Embora este se trate de um estudo de caráter exploratório e não exaustivo, esperamos que possa contribuir para o desenvolvimento de pesquisas futuras relacionadas às reformas educacionais e às implicações da participação de empresas e institutos privados na educação pública.

\section{Referências}

ARAÚJO, P. P. B.; LEITE, F. M. C. O ensino remoto e a racionalidade neoliberal: representações de economia em um texto prescritivo e em materiais didáticos. In: OLIVEIRA, K. C. C. et al. (org.). Reflexões sobre o ensino de línguas e literatura, formação docente e material didático. São Carlos: Pedro \& João Editores, 2020. p. 289-310.

BALL, S. J. Educação Global S. A.: novas redes de políticas e o imaginário neoliberal. Tradução Janete Bridon. Ponta Grossa: UEPG, 2014.

BAUMAN, Z. Amor líquido: sobre a fragilidade dos laços humanos. Tradução Carlos Alberto Medeiros. Rio de Janeiro: Zahar, 2004.

BAUMAN, Z. Modernidade líquida. Tradução Plínio Dentzien. Rio de Janeiro: Zahar, 2001. BRONCKART, J. P. Atividade de linguagem, textos e discursos: por um interacionismo sociodiscursivo. 2. ed. Trad. Anna Rachel Machado e Péricles Cunha. São Paulo: EDUC, 2012.

BRONCKART, J. P. Atividade de linguagem, discurso e desenvolvimento humano. Campinas, SP: Mercado de Letras, 2006.

BRONCKART, J. P. Atividade de linguagem, textos e discursos: por um interacionismo sociodiscursivo. São Paulo: EDUC, 1999

DELORS, J. et al. Educação: Um tesouro a descobrir. Relatório para a UNESCO da Comissão Internacional sobre Educação para o século XXI. 8. ed. São Paulo: Cortez; Brasília, DF: MEC: UNESCO, 2003. 
Volume 16 - Número 1 - jan/jul de 2021

GIL, A. C. Métodos e técnicas da pesquisa social. 6. ed. São Paulo: Atlas, 2008. ICE. INSTITUTO DE CORRESPONSABILIDADE PELA EDUCAÇÃO. Sobre o ICE. [S. l.]: ICE, [2015]. Disponível em: http://icebrasil.org.br/sobre-o-ice/. Acesso em: 30 out. 2019. ICE. INSTITUTO DE CORRESPONSABILIDADE PELA EDUCAÇÃO. Modelo de Gestão: Tecnologia de Gestão Educacional: Ensino Médio. 2. ed. Recife: ICE, 2019. ICE. INSTITUTO DE CORRESPONSABILIDADE PELA EDUCAÇÃO. Manual operacional: Modelo de Gestão - Tecnologia Empresarial Socioeducacional (TESE): uma nova escola para a juventude brasileira. [S. l.]: ICE, [2008].

JOÃO AZEVEDO anuncia implantação de escolas integrais em todos os municípios da Paraíba. ParaibaOnline, João Pessoa, 25 jan. 2021. Disponível em:

https://paraibaonline.com.br/2021/01/joao-azevedo-anuncia-implantacao-de-escolas-integraisem-todos-os-municipios-da-paraiba/. Acesso em: 26 mar. 2021.

LAMB, I. T. et al. Análise da Tecnologia Empresarial Odebrecht (TEO): uma análise a partir dos conceitos do projeto organizacional de Galbraith. Interciencia, v. 43, n. 7, p. 475-483, 2018. Disponível em: https://www.redalyc.org/jatsRepo/339/33957461003/html/index.html. Acesso em: 28 mar. 2021.

LAVAL, C. A escola não é uma empresa: o neoliberalismo em ataque ao ensino público. Tradução Mariana Echalar. São Paulo: Boitempo, 2019.

LEITE, E. João Azevêdo discute plano de vacinação no Consórcio Nordeste e marca reunião para aprovação emergencial das vacinas. ClickPB, João Pessoa, 28 dez. 2020. Disponível em: https://www.clickpb.com.br/paraiba/joao-azevedo-discute-plano-de-vacinacao-no-consorcionordeste-e-marca-reuniao-para-aprovacao-emergencial-das-vacinas-298592.html. Acesso em: 18 jan. 2021.

LIBÂNEO, J. C. Políticas educacionais no Brasil: desfiguramento da escola e do conhecimento escolar. Cadernos de Pesquisa, v. 46, n. 159, p. 38-62, jan./mar. 2016. Disponível em: https://www.scielo.br/pdf/cp/v46n159/1980-5314-cp-46-159-00038.pdf. Acesso em: 29 mar. 2021.

MOITA LOPES, L. P. (org.). Por uma linguística aplicada INdisciplinar. São Paulo: Parábola Editorial, 2006.

PENNYCOOK, A. Uma Linguística Aplicada Transgressiva. In: MOITA LOPES, L. P. (org.). Por uma linguística aplicada INdisciplinar. São Paulo: Parábola Editorial, 2006. p. 67-84.

REICHMANN, C. L. A professora regente disse que aprendeu muito: a voz do outro e o trabalho do professor iniciante no estágio. Raído, Dourados, v. 8, n. 15, p. 33-44, 2014. RODRIGUES, A. C. S. Escola Cidadã Integral: proposições curriculares para jovens do ensino Médio. Revista Espaço do Currículo, João Pessoa, v. 12, n. 1, 2 mar. 2019.

Disponível em: https://periodicos.ufpb.br/index.php/rec/article/view/ufpb.19831579.2019v12n1.41984 Acesso em: 5 jan. 2021.

SANTOS, V. B. M. P. As características léxico-gramaticais de um manual de gestão a partir da análise multidimensional de Biber. The ESPecialist, v. 24, n. 2, p. 201-227, 2003.

Disponível em: https://revistas.pucsp.br/index.php/esp/article/view/9484/7047. Acesso em: 29 mar. 2021.

SILVA, L. R. C. et al. Pesquisa documental: alternativa investigativa na formação docente. In: CONGRESSO NACIONAL DE EDUCAÇÃO. 9., 2009, Curitiba. Anais [...]. Curitiba: PUC-PR, 2009. Disponível em: https://educere.bruc.com.br/arquivo/pdf2009/3124_1712.pdf. Acesso em: 21 mar. 2021. 